\title{
Derecho de acceso a la información pública
}

\section{MEI \\ II, vol. 3 \\ $\mathrm{n}^{0} 5$}

\author{
Verónica Gauchi Risso \\ Departamento de Documentación. Facultad de Humanidades. \\ Universidad Nacional de Mar del Plata.
}

Recibido el 16-09-2012

Aceptado en 18-12-2012

\begin{abstract}
Resumen
$\mathrm{Si}$ bien toda necesidad social no engendra un derecho, para una necesidad tan fundamental, objetiva y universal como el acceso a la información pública se hace necesaria la existencia de un derecho que la ampare para que cualquier ciudadano bien informado pueda cumplir con su papel, teniendo en cuenta que el derecho de acceso a la información pública condiciona una nueva forma de democracia, la democracia participativa. Este trabajo describe las relaciones existentes entre la sociedad, el derecho de acceso a la información y el acceso a los documentos públicos. Como conclusión se manifiesta que el derecho de acceso a los documentos públicos es el derecho a conocer qué hacen las autoridades, en tanto es un derecho humano básico para la defensa de los derechos esenciales de los ciudadanos frente a los posibles abusos de la Administración.
\end{abstract}

\section{Palabras clave}

Acceso a la información; Derecho a la información; Documentos públicos.

Right of access to public information

Abstract

While any social need not beget a right to a need so fundamental, objective and universal such as access to public information, it is necessary the existence of a right for protection for any informed citizen to fulfill its role, taking note that the right of access to public information determines a new form of democracy, participatory democracy. This paper describes the relationships between society, the right of access to information and access to public documents. As a conclusion it appears that the right of access to public documents is the right to know what the authorities do, as it is a basic human right to defend the basic rights of citizens against possible abuses of government.

\section{Keywords}

Information Access; Information right; Public documents.

\section{INTRODUCCIÓN}

En la actualidad, la información aparece como un hecho y un problema, y es normal que a esta situación se responda con un derecho: el del acceso a la información, cuyos fundamentos se encuentran en la doble consideración del hombre contemporáneo: persona en situación histórica y ciudadano, puesto que para poder desenvolverse en la sociedad, se necesita información.

El derecho a la información tiene su lugar entre los derechos elementales del hombre; nace ante la necesidad de reglamentar y organizar el ejercicio de un derecho natural, reconocido con estas 
características en las leyes fundamentales de los diversos países constituidos en el ámbito jurídico-político al modo de Estados de derecho. El derecho de acceso a la información pública constituye uno de los pilares esenciales para el funcionamiento de la democracia. Este derecho que se encuentra enmarcado dentro de la tercera generación de los derechos fundamentales del hombre adquiere significación plena y efectiva en relación con un contexto temporal determinado y con una realidad socioeconómica y cultural concreta.

Los profesionales del ámbito de la información bien sabemos acerca de los problemas que acarrea la falta de información y sobre las consecuencias de estar mal informado; la información es un factor de progreso en la sociedad contemporánea que aparece como una exigencia para el "bien común". Para poder actuar en la sociedad el hombre requiere de información, y si bien toda necesidad no engendra un derecho, a una necesidad tan fundamental, objetiva y universal como el acceso a la información se hace necesaria la existencia de un derecho que la ampare, puesto que cualquier ciudadano no cumplirá con su papel más que si está bien informado.

\section{MATERIAL Y MÉTODO}

Se desplegará un estudio de carácter descriptivo, pues-to que solamente se detallarán las propiedades del ob-jeto de estudio en forma independiente y de corte longitudinal, dado que el trabajo ofrece un análisis de las transformaciones políticas y sociales que posibilitaron el surgimiento del concepto Derecho de acceso a la información.

\section{MARCO CONCEPTUAL}

\subsection{Generaciones de derechos fundamentales y el origen del derecho a la información}

Cuando se habla de derechos fundamentales, se está hablando de generaciones de derechos humanos, marcados en diferentes momentos históricos del mundo contemporáneo, y por diferentes modelos que asumió el Estado a lo largo del tiempo. Examinaremos a continuación el origen de estos derechos, ligado al nacimiento del Estado, por la inconformidad de la población con el régimen absolutista.

\subsection{Primera generación de derechos fundamentales: la libertad, la propiedad, la seguridad y la resistencia a la opresión}

La primera generación de derechos humanos se contextualiza en dos momentos históricos sucesivos: el primero, las denominadas revoluciones burguesas del siglo XVIII, y luego, en la etapa de consolidación de la revolución liberal, con el advenimiento del llamado Estado Liberal de Derecho, marcando el tránsito de los antiguos derechos estamentales medievales a los modernos derechos humanos.

En el plano de la titularidad corresponden a todos los seres humanos por el simple hecho de serlo, y en el plano de la naturaleza jurídica, pasan a ser instrumentos del derecho público. Con el movimiento de independencia de las colonias inglesas de América del Norte, el triunfo del Iluminismo y las ideas de la Ilustración, se plasman por escrito los primeros derechos fundamentales en la Declaración de Derechos del Buen 
Pueblo de Virginia, el 12 de junio de 1776, e inmediatamente en la Declaración de Independencia Norteamericana, el 4 de julio de 1776. En el tex to de Virginia se inicia la concepción liberal de los derechos individuales, que sustrae determinadas esferas del hombre al poder del Estado, al constituirse el Estado y la sociedad civil mediante el contrato originario según la tesis de John Locke, por la que los hombres se desprenden de una parte de sus derechos naturales innatos, con el único objeto de conseguir ver garantizadas esas esferas naturales de libertad por el Estado, que además garantiza, en caso de ataque, la legítima corrección y sanción.

En Europa, las tesis del Iluminismo y las ideas revolucionarias de Jean Jacques Rousseau se consagraron en la primera Carta de derechos francesa, la Declaración de los Derechos del Hombre y del Ciudadano, del 26 de agosto de 1789. Con vocación universalista, la declaración de 1789 se dirige a toda la humanidad, afirmando los derechos naturales e imprescriptibles de los hombres: la libertad, la propiedad, la seguridad y la resistencia a la opresión. La Revolución Francesa trae consigo una nueva concepción de la organización social, en la que los derechos humanos constituyen principios fundamentales de articulación o estructuración en el plano nacional. En América, el siguiente paso vino dado por la incorporación de las declaraciones al constitucionalismo. Hasta la Constitución de Apatzingán, de 1814 (México), las declaraciones de derechos no se integraron en el articulado constitucional como principios directamente ejecutables ante los tribunales. De esta forma nacen los derechos públicos de los ciudadanos (García Ramírez, 2002).

La primera generación de derechos humanos es fruto de la ideología liberal y de la mentalidad burguesa. Reconoce los derechos naturales, inalienables y sagrados del hombre, y en este sentido proclama los derechos que corresponden al hombre por naturaleza desde presupuestos individualistas: la libertad, la propiedad, la seguridad y la resistencia a la opresión. Así se mantuvieron durante todo el siglo XIX, el siglo del liberalismo y del modelo del Estado liberal de derecho. Este modelo de Estado, aparentemente despolitizado, que no persigue una actuación transformadora del modelo social y consagra la neutralidad y el abstencionismo de las Administraciones públicas, no podía interferir en el plano de las relaciones sociales para regular la cultura.

Sin embargo, pueden observarse claros antecedentes de los derechos culturales en esta primera etapa de positivación de los derechos fundamentales. En la De-claración de los Derechos el Hombre y el Ciudadano, incluida en el Proyecto de Constitución Republicana Francesa, del 24 de junio de 1793, en el artículo 22 se menciona el derecho a la instrucción pública, que hoy podríamos entender como derecho a la educación, un auténtico derecho cultural.

\subsection{Segunda generación de derechos fundamentales: socia-les, económicos y culturales}

El individualismo y la neutralidad del Estado liberal de derecho no podían satisfacer las exigencias de libertad e igualdad de los sectores sociales más deprimidos; el modelo liberal de Estado generó serios problemas so-ciales, lo que condujo hacia un nuevo modelo de Esta-do: el Estado social de derecho, que se instituye me-diante la figura del Estado intervencionista, que actúa sobre los procesos socioeconómicos en 
defensa de los más desfavorecidos socialmente. Con él surge la idea de procura existencial, que está en la base de los nue-vos derechos fundamentales. El poder público tiene la tarea de proporcionar a la generalidad de los ciudada-nos las prestaciones necesarias y los servicios públicos adecuados para que puedan desarrollar plenamente su personalidad. Puede considerarse que, a comienzos de la primera década del siglo XX, los derechos económicos, sociales y culturales alcanzan su verdadero estatuto jurídico-formal en los textos constitucionales. La Constitución política de los Estados Unidos Mexicanos, de 1917, y la Constitución del Reich Alemán, o Constitución de Weimar, de 1919, son las primeras que los formulan expresamente.

El fenómeno se generaliza a partir de la II Guerra Mun-dial, con el desarrollo constitucional de los nuevos Es-tados surgidos al finalizar el conflicto bélico universal, y como consecuencia de los procesos de descoloni-zación. Estos derechos se consolidan al amparo de la Organización de Naciones Unidas, con documentos internacionales y regionales. Los derechos de segunda generación surgen como respuesta de los sistemas jurídicos constitucionales a las necesidades vitales del hombre, satisfacen todas aque-llas aspiraciones sociales que fueron desatendidas, cuando no despreciadas, por el Estado liberal, y garan-tizan la participación de los ciudadanos en las diversas esferas de la vida social, económica y cultural. Los derechos culturales alcanzan carta de naturaleza en el modelo histórico de Estado social de derecho y bajo el principio de igualdad social y económica en las relaciones sociales; cubren la protección de los indivi-duos y los grupos en el ámbito de los vínculos que les unen a su propia herencia cultural. Constituyen este grupo el derecho a la conservación y desarrollo de la propia cultura, el derecho a participar en la vida cultu-ral y el derecho a la protección de las creaciones cientí-ficas, literarias y artísticas (Castro Cid, 1993).

\subsection{Tercera generación de derechos fundamentales: la re-volución tecnológica, la ecología y el patrimonio cultural}

Las transformaciones sociales, económicas, políticas, culturales y tecnológicas acaecidas en la segunda mitad del siglo XX impusieron, tanto a la doctrina como a la legislación, la ampliación del sistema de derechos fun-damentales, dando respuesta a las nuevas necesidades vitales, sentidas por el hombre contemporáneo como valores jurídicamente exigibles e irrenunciables. Los derechos de tercera generación dan respuesta a la erosión y degradación del sistema de derechos funda-mentales ante determinados usos de las nuevas tecno-logías, y redimensionan las relaciones de los hombres con su ambiente y marco de convivencia. La tercera generación de derechos se encuentra en plena conso-lidación y desarrollo. Incluye los intereses ecológicos y medioambientales, el uso de la informática, la tele-mática, la tecnología, y los relacionados con el mundo de la cultura. El pleno desarrollo del hombre implica la necesaria asimilación de los valores que reflejan los bie-nes culturales, cuyo instrumento máximo es el derecho a acceder y disfrutar del patrimonio cultural.

Este proceso de positivación internacional de los dere-chos fundamentales se inició bajo la Sociedad de Na-ciones y fue trágicamente interrumpido por la II Guerra Mundial. Los horrores de esta contienda condujeron a la humanidad a tomar conciencia acerca de la protec-ción de los derechos fundamentales, que había dejado 
de ser una cuestión doméstica de los Estados para convertirse en un auténtico problema internacional.

\subsection{Derecho de acceso a la información}

El derecho de acceso a la información nace ante la necesidad de reglamentar y organizar el ejercicio de un derecho natural, reconocido con estas características en las leyes fundamentales de los diversos países organizados en al ámbito jurídico-político al modo de los estados de derecho. La configuración inicial del concepto de acceso a la información se origina en la "Declaración francesa de los Derechos del Hombre y del Ciudadano" en 1789 (Artículos $14^{\circ}$ y $15^{\circ}$ ) en la cual se encontraba referido a la facultad de solicitar cuentas a todo agente público sobre su administración; 150 años después fue ampliado por la "Declaración de las Naciones Unidas" con el concepto de libertad de información.

Se entiende por derecho de acceso a la información al conjunto de normas jurídicas que regulan las actividades relativas a la educación, la ciencia y la tecnología, los derechos de autor, el patrimonio cultural, la promoción cultural de las artes y los medios de comunicación. Este derecho puede ser considerado como la base sustantiva del derecho a la comunicación y uno de los pilares fundamentales del Derecho Internacional de los Derechos Humanos. Es un pilar del Estado de derecho; no puede haber vigencia del Estado de derecho sin derecho a la información, ya que éste, a su vez, garantiza la libertad de pensamiento. En consecuencia, sin derecho de acceso a la información tampoco podría ejercerse el control ciudadano de la gestión pública.

A lo largo de los siglos este derecho ha ido apareciendo en las constituciones o leyes fundamentales de los Estados Democráticos, ligado al despertar del derecho constitucional que acabó por encontrar una formulación terminológica clara en la Encíclica "Pacem in Terris" (1963) del Papa Juan XXIII denominado el Pontífice de los Derechos Humanos, en la que se reconoce su entidad como derecho fundamental. Aunque los estudios sobre la doctrina del acceso a la información, como hoy se la conoce, especialmente se remiten a la ley "Freedom of Information Act" de los Estados Unidos de 1966; sin embargo hay quienes se remontan a una "Real Ordenanza Sueca" de 1766 referida a la libertad de prensa en la cual se contemplaba el acceso a la documentación pública. La ley sobre libertad de información de los Estados Unidos de 1966 consagraba un principio que es piedra liminar para todo el sistema de información pública: "la información poseída por la Administración pertenece al pueblo", de este modo queda consagrado el principio republicano sobre la publicidad de los actos públicos. Desde los orígenes del sistema republicano, "la publicidad de los actos de gobierno" se consideró un principio esencial, en contraposición con el secreto y la oscuridad en el ejercicio del poder y en el manejo burocrático propio de los regímenes preconstitucionales (Pérez y Makowiak, 2004).

En el contexto latinoamericano el derecho de acceso a la información se encuentra reconocido en la "Convención Americana de los Derechos Humanos o Pacto de San José de Costa Rica”, y en legislación complementaria; que establece un conjunto de preceptos vinculado tanto con el sujeto que informa como con quien recibe esa información.

El acceso a la información como parte de los derechos humanos y como parte de 
los derechos fundamentales constitucionales, así como su condición indispensable para el ejercicio de la democracia, actualmente, despliega facetas variadas. Con relación al informador, el derecho de acceso a la información se establece en las siguientes facultades:

La publicidad de los actos de gobierno,

- Derecho a investigar y buscar informaciones y opiniones,

- Derecho a difundir informaciones de relevancia pública por cualquier medio y opiniones,

- Derecho a emitir informaciones y opiniones,

- Derecho a no ser censurado ni objeto de restricciones preventivas en forma explícita o implícita, directa o indirecta, a excepción de medidas destinadas a proteger la moral de los menores o adolescentes, o en casos de estados de excepción constitucional,

- Derecho de acceso a las fuentes de información,

- Derecho al secreto profesional periodístico y a la reserva de las fuentes,

- Derecho a la cláusula de consciencia,

- Derecho al acceso y utilización de instrumentos y medios naturales o tecnológicos necesarios que permitan emitir las opiniones e informaciones.

En relación con el informado, las facultades son:

- Derecho a recibir informaciones y opiniones,

- Derecho a seleccionar la información que recibe y los medios a través de los cuales recibirla,

- Derecho a ser informado veraz y oportunamente,

- Derecho a que sea preservada su honra, datos personales y vida privada (habeas data),

- Derecho a obtener una rectificación o respuesta,

- Derecho a solicitar la imposición judicial de responsabilidades civiles y penales en los casos determinados por el ordenamiento jurídico.

En tanto derecho personal, el acceso a la información, se presenta como correlato de la libertad de expresión, y específicamente, de los derechos de libertad consagrados al resguardo del campo de la autonomía personal y el ejercicio de la libertad de expresión; la Corte Interamericana de Derechos Humanos ha sostenido que: "La libertad de expresión es una piedra angular en la existencia misma de una sociedad democrática. Es indispensable para la formación de la opinión pública. Es también conditio sine qua non para que los partidos políticos, los sindicatos, las sociedades científicas y culturales, y en general, quienes deseen influir sobre la colectividad puedan desarrollarse plenamente. Es, en fin, condición para que la comunidad, a la hora de ejercer sus opciones, esté suficientemente informada. Por ende, es posible afirmar que una sociedad que no está bien informada no es plenamente libre" (Corte Interamericana de Derechos Humanos, 1985: 21). Lo cual 
significa que este es un derecho de doble vía, que no se establece en un único sentido, sino que comprende tanto la libertad expresión y de emitir opiniones así como el derecho de buscar, investigar, recibir, publicar y difundir el conocimiento de hechos, datos o situaciones determinadas de relevancia pública, sin censura ni restricciones preventivas.

Este derecho puede ser considerado como la base sustantiva del derecho a la comunicación y uno de los pilares fundamentales del Derecho Internacional de los Derechos Humanos, es un pilar de todo Estado de Derecho porque no puede haber vigencia del Estado de derecho sin derecho a la información que garantice la libertad de pensamiento esencial para el desarrollo del ser humano.

\subsection{El derecho de acceso a los documentos públicos y los archivos}

El derecho de acceso a la información se manifiesta especialmente en el principio de difusión de todos los actos de la administración pública, que se encuentra formalizado en: la publicación de los actos administrativos, la comunicación individualizada de los actos administrativos a quienes puedan estar interesados y la comunicación como respuesta a una demanda concreta de los administrados, incluida la posibilidad de obtener vista y copia de los documentos solicitados, obviamente estableciendo las garantías razonables de conservación del documento-fuente, sea o no original. El derecho de vista se encuentran consagrado en las leyes fundamentales como una garantía procesal del ciudadano, la "vista" de las actuaciones administrativas se considera un importante elemento de la garantía de la defensa o del debido proceso (Escola, 1981); recordemos que el acceso a la información, la participación del ciudadano en el proceso decisorio y el acceso a la justicia constituyen los tres pilares de lo que hoy en día se denomina democracia participativa.

La difusión de la acción administrativa garantiza mejor su rectitud y tiende a institucionalizar las presiones, buena prueba de ello es la publicidad de los concursos administrativos. Este principio refuerza las posibilidades de defensa de los individuos frente a las potestades administrativas y ofrece elementos para el diálogo, la crítica y la oposición, en resumen, permite contrapesar las prerrogativas clásicas de la Administración. No puede existir una Administración eficaz sin control externo y no es posible controlarla realmente sin información. El derecho a la información administrativa o a la documentación debe canalizarse en tres vías: la publicación general sistemática, la comunicación individualizada a los que puedan estar interesados, y la comunicación como respuesta a una demanda concreta de los administrados, incluida la posibilidad de reproducción de los documentos solicitados, con todas las garantías razonables de conservación del documento-fuente, original o no.

Al derecho del ciudadano a ser informado corresponde el deber de la administración gubernamental de informar con veracidad, si bien este principio no es novedoso, sí lo son los progresos legislativos en algunos países para establecer normas claras y eficaces sobre la apertura de archivos y la atención de solicitudes de información que formulen los ciudadanos, con la excepción de aquellos documentos que se encuentren expresamente excluidos o reservados. El principio general es que la información de las reparticiones gubernamentales en última instancia no tiene otro 
dueño legítimo que el pueblo, según la fórmula acuñada por la legislación norteamericana, el acceso a determinados datos puede ser necesario para cualquier persona por múltiples razones de interés particular, pero además es importante para que se pueda controlar desde todos los ámbitos de la sociedad la regularidad y la eficacia de la gestión de los funcionarios.

Para que el derecho de acceso a la información pública pueda ser ejercido los poderes públicos deben concretar la aplicación de determinadas de medidas que garanticen el acceso a los archivos administrativos y registros públicos, tal como hoy se concibe a este derecho en relación con la documentación pública, porque son los archivos administrativos y registros públicos aquellos que tienen a su cargo la organización, conservación y difusión de todos los documentos generados o recibidos en las administraciones públicas como producto del ejercicio de las funciones y actividades que les han sido encomendadas y con el fin de alcanzar los objetivos y metas de la entidad. El cúmulo de esa producción documental es lo que da origen a los fondos de los archivos administrativos.

"La documentación administrativa como disciplina especializada tiene como objeto estudiar los procesos de creación y transmisión de información objetivada en el seno de la Administración Pública [...] podríamos hablar de la Documentación aplicada a la Ciencia de la Administración, y de la Documentación para las Administraciones Públicas, o de ambos conceptos: Documentación Administrativa y Documentación para las Administraciones Públicas, refiriéndonos a aquella Documentación generada por los poderes públicos en el ejercicio de un acto administrativo, o conjunto de acciones regladas por las normas de procedimiento, reflejando el funcionamiento, actividad y gestión de la Institución Pública, asi como las competencias y funciones del órgano que lo genera” (Fernández Bajón, 1996: 68).

Durante las últimas décadas y en virtud de las decisiones políticas asumidas, los archivos han conseguido notables posiciones dentro de las estructuras institucionales, se han convertido en potenciales centros de información y resultan ser instrumentos imprescindibles al momento de gestionar de manera eficiente toda la documentación de la administración pública; como consecuencia los archivos han dejado de ser oscuros depósitos de papeles caducos e inutilizables para pasar a ser efectivos instrumentos de la gestión gubernamental y de la conciencia social.

\section{CONCLUSIONES}

El derecho de acceso a la información pública, no es ni más ni menos que el derecho a conocer qué hacen las autoridades públicas; es tanto un derecho humano básico para la defensa de los propios derechos esenciales de las personas frente a los posibles abusos de la Administración, como un componente inseparable del derecho a dar y recibir información y de la libertad de expresión.

Para materializar el derecho de acceso a la información debe haber una estrecha relación entre la sociedad y el Estado, que tienen que interactuar en forma conjunta para tomar en cuenta nuevos comportamientos, actitudes y valores de una sociedad 
cada vez más globalizada, y advertir el valor estratégico del conocimiento, la información y la lectura en el desarrollo y la democratización.

En el ámbito de la administración pública el ejercicio del derecho de acceso a la información contribuye a que los ciudadanos puedan evaluar de mejor manera el desempeño de los gobernantes, fortalece la democracia y otorga una herramienta concreta para la transparencia del sistema; no puede existir una Administración eficaz sin control externo y no se puede controlar realmente sin información, en consecuencia, sin derecho de acceso a la información no podría ejercerse el control ciudadano sobre la gestión pública. El efectivo ejercicio de este derecho permite a los ciudadanos, entre otras cosas, monitorear y ser partícipe del control de la gestión pública; formar opinión sobre diversos temas, participar debatiendo con fundamentos y fomentar la transparencia en la gestión del Estado mejorando la calidad de sus instituciones.

El derecho de acceso a la información pública tiene amplia recepción normativa de distinto rango; así, encontramos disposiciones relativas al derecho de acceso en el ámbito de las instituciones públicas, el derecho de acceso a archivos administrativos y en general a los registros públicos, con una regulación específica en razón de la materia, referida a cuestiones estadísticas, medioambientales, tributarias, administrativas, etc.; pero para garantizar el derecho a la información se deben vencer primero las dificultades procesales que permitan el reconocimiento de las acciones públicas que posibiliten el acceso de todos los habitantes a la información pública. Si bien es cierto que no hay peor ley que la que no se cumple, también lo es que sin ley no existe siquiera la posibilidad formal de concretar muchos de los derechos que, por no estar expresamente escritos devienen tan sutiles e intangibles en nuestra vida cotidiana, que lindan con su inexistencia. Mientras las normas legales, constitucionales e, in-cluso, supra-constitucionales, acreditan de manera intensa los principios de publicidad de los actos de gobierno, el acceso de los interesados a las actuaciones administrativas (salvo que ellas sean calificadas por acto expreso y motivado como re-servadas o confidenciales), criterios de publicidad, razonabilidad, defensa del adminis-trado, control de la actividad administrativa, eficiencia y eficacia de la actuación adminis-trativa, lo cierto es que en muchas oportunidades para poner en práctica de tales disposiciones hay que sortear una cantidad de obstáculos que agotan a cualquiera.

Nuestra tradición administrativa, nuestra cultura, es devota del silencio, el secreto y la reserva y no de la publicidad de las normas que establecen las pautas de actua-ción de los administradores públicos (Pomed Sanchez, 1997), para ello se hacen necesarias campañas coordinadas por parte de todos los poderes del Estado con el objeto de dar a conocer a la ciudadanía la posibilidad que tiene de exigir al Estado el cumplimiento de la normativa existente; porque ciertamente es escaso el rol de la sociedad civil en éste campo que resulta fundamental para lograr una mejor práctica de ésta herramienta vital para la democracia. 


\section{NOTAS}

1. Los derechos fundamentales son aquellos inherentes al ser humano, pertenecen a toda persona en razón a su dignidad humana. Cuando se habla de generaciones de derechos humanos o fundamentales se habla de derechos enmarcados en diferentes momentos históricos del mundo contemporáneo atravesados por diferentes modelos que asumió el Estado a lo largo del tiempo.

2. La doctrina de los derechos humanos pone el centro de atención en los bienes individuales que han de ser garantizados y promovidos y en la participación en los bienes sociales que le corresponde a cada persona en razón de su particular dignidad; desde la perspectiva del bien común, que atiende particularmente a la dimensión social y comunitaria del hombre, el respeto a los derechos humanos es una de sus condiciones básicas en cuanto asegura la buena marcha de la sociedad y facilita el que la comunidad política alcance sus propios fines

3. La expresión Derecho Natural hace referencia a una corriente de pensamiento jurídico presente por más de 25 siglos; su idea fundamental es la tesis de la existencia de un Derecho anterior a cualquier norma jurídica positiva, es decir, de origen humano, denominado precisamente Derecho Natural.

4. Se consideran leyes fundamentales las que tienen rango constitucional.

5. En una sociedad democrática los derechos y libertades inherentes a la persona, sus garantías y el Estado de Derecho constituyen una tríada, cada uno de cuyos componentes se define, completa y adquiere sentido en función de los otros, el estado de derecho es donde la ley es el instrumento preferente para guiar la conducta de los ciudadanos.

\section{REFERENCIAS}

Castro Cid, B. de (1993). Los derechos económicos, sociales y culturales: análisis a la luz de la teoría general de los derechos humanos. León: Universidad de León.

Corte Interamericana de Derechos Humanos (1985). Opinión consultiva OC-5/85 del 13 de noviembre: la colegiatura obligatoria de periodistas: arts. 13 y 29 Convención Americana sobre Derechos Humanos. Disponible en:

http://biblioteca.corteidh.or.cr:8070/alipac/YUIWNTVZNWCDCIDYBHIL-00027/find-scan? SEQ=000086969 [Consulta: 17 de diciembre de 2012].

Escola, J. H. (1981). Tratado General de Procedimiento Administrativo. Buenos Aires; Depalma.

Fernández Bajón, M. T. (1996). "Documentación administrativa: una revisión de las tipologías documentales administrativas comunes”. Revista General de Información y Documentación, vol. 6, № 2, pp. 67-90.

García Ramírez, S. (2002). Constitución de Apatzingan. EN: García Ramírez, S. Temas de derecho. México: Instituto de Investigaciones Jurídicas, UNAM, pp. 169-177.

Juan XXIII (Papa). (1993). Pacem in terris: la paz entre todos los pueblos, fundada sobre la verdad, la justicia, el amor y la caridad. Madrid: Apostolado de la Prensa, 1963.

Pérez, E. y Makowiak, J. (2004). "El Derecho de Acceso a la Información en Europa y América Latina: un enfoque constitucional”. Revista electrónica de Derecho ambiental, № 10 (may). Disponible en:

http://huespedes.cica.es/aliens/gimadus/10/DERECHOACCESO.htm [Consulta: 10 de agosto de $2012]$.

Pomed Sánchez, L. (1997). "El acceso a los archivos administrativos: el marco jurídico y la práctica administrativa”. Revista Administración Pública(R AP), No 152, pp. 439-440. 